\title{
7. Measuring innovation in all economic sectors
}

\subsection{INTRODUCTION}

Chapter 6 presented a general definition of innovation applicable in all economic sectors and an application of the general definition to the business sector. Chapter 7 now provides definitions of the economic sectors, as specified in the System of National Accounts, 2008 (2008 SNA) (EC et al. 2009). Also provided are examples of statistical measurement of innovation in the sectors, where they are available, and suggestions where they are not. In the case of the business sector, consideration is given both to the sector-specific definition used in the Oslo Manual (OECD/ Eurostat 2018: para. 3.9) and to the general definition.

Once the economic sectors are defined, the focus of the chapter is on measurement. As discussed in Chapter 6, affirmative responses to two survey questions are required to confirm the presence of innovation. The first is a question asking if there is a 'new or improved product or process (or combination thereof) that differs significantly from the unit's products or processes'. The response to this question requires a judgement on the part of the respondent. The second question does not. It asks what is done by the unit with that product or process. Has the product been 'made available to potential users'? Or, has the process been 'brought into use by the unit'? What is done with the product or process is observable and it either has happened or not. It is not a matter of judgement. A survey statistician can, from the answers to these two questions, infer the presence of innovation.

\subsection{THE SYSTEM OF NATIONAL ACCOUNTS}

The System of National Accounts (SNA) serves as a coordinating framework for data collection and indicators that support the understanding of the economy and the development and monitoring of economic policy 
(EC et al. 2009: para. 1.57). The best known indicator in the SNA is the Gross Domestic Product (GDP). 9

The SNA provides a flow of information that can be used for monitoring, analysis and evaluation of data over time. It also deals with links of the economy to the rest of the world (EC et al. 2009: para. 1.2). Directly relevant to measuring innovation in all economic sectors is the ability to 'observe and analyse the economic interactions taking place between different sectors of the economy' (EC et al. 2009: para. 1.3). The SNA supplies a conceptual framework for ensuring the consistency of the definitions and classifications used in different, but related, fields of statistics. It also acts as an accounting framework to ensure the numerical consistency of data drawn from different sources in the system (EC et al. 2009: para. 1.57).

From the first edition of the Oslo Manual (OECD 1992), the conventions of the SNA have been used, the most common of which is 'product' to refer to goods and services (EC et al. 2009: para. 2.36). In the fourth edition of the Oslo Manual (OECD/Eurostat 2018), Chapter 2 introduces the SNA, and its use in the manual. The term 'unit' in the general definition of innovation refers to the 'institutional unit' in economic sectors. The definition of an 'institutional unit' is found in the $2008 \mathrm{SNA}$, para. 4.2:

An institutional unit is an economic entity that is capable, in its own right, of owning assets, incurring liabilities and engaging in economic activities and in transactions with other entities.

The SNA (EC et al. 2009: para. 4.24) assigns all residential institutional units to one of five sectors, the:

- non-financial corporations sector

- financial corporations sector

- general government sector

- non-profit institutions serving households sector (NPISHs)

- households sector.

For use here, and to conform with the Oslo Manual, the first two sectors are combined to become the 'business sector' (see more in the next section). For the fifth sector, 'Households' is replaced with 'household'

Innovation in the public sector is an area of interest and the SNA provides the following definition. 'The public sector includes general government and public corporations.' However, some effort is required 
to decide where non-profit institutions are placed, and the same question arises for institutions which may be public institutions or are part of general government. This is discussed in the 2008 SNA (EC et al. 2009: 436 , Defining the general government and public sectors).

The 2008 SNA is the most recent in a series of SNA manuals produced by international and supranational organisations and used by countries to guide their SNA and the production of key indicators such as GDP. Decisions taken by the SNA community have an impact on the measurement of innovation and of innovation activities. An example is the decision to capitalise expenditure on software development, making it a capital investment and no longer an expense (EC et al. 1994: 648). In the following revision of the SNA, the Canberra II Group was responsible for the recommendation to capitalise R\&D. In the course of the deliberations, members of Canberra II and NESTI met twice, once in Berlin in 2006 and once in Paris in 2007. In the 2008 revision, R\&D was capitalised (EC et al. 2009: xlviii).

From the perspective of measurement, the SNA has capitalised two out of the eight business innovation activities (EC et al. 2009: para. 1.36). The remaining six are: engineering, design and other creative work activities; marketing and brand equity activities; intellectual property (IP)-related activities; employee training activities; activities related to the acquisition or lease of tangible assets; and innovation management activities. Haskel and Westlake (2018) provide a relevant discussion of 'the rise of the intangible economy'.

This introductory section is deliberately short, but it connects the terms in the definitions of innovation (product and unit) to the 2008 SNA, links the four economic sectors in the Oslo Manual to the five sectors in the SNA and it defines the public sector. More high-level information is found in Chapter 2 of the SNA Manual 2008 and a more detailed discussion of institutional units and sectors is found in Chapter 4 of the same manual. Finally, the link is made between business innovation activities in the fourth edition of the Oslo Manual and the 2008 SNA. 


\subsection{BUSINESS SECTOR}

The business sector, here and in the Oslo Manual, is the combination of the SNA non-financial and the financial corporations sectors. They are defined as follows:

Non-financial corporations are corporations whose principal activity is the production of market goods or non-financial services. (EC et al. 2009: para. 4.94)

Financial corporations consist of all resident corporations that are principally engaged in providing financial services, including insurance and pension funding services, to other institutional units. (EC et al. 2009: para. 4.98)

When these are combined, they cover all resident corporations that provide goods or services.

\subsubsection{Business Innovation and the Market}

In the fourth edition of the Oslo Manual, processes, marketing methods and organisational methods of the third edition are combined into processes with six sub-categories (OECD/Eurostat 2018: Table 3.1), discussed in Chapter 6, Section 6.2. The definition of business innovation is the following:

A business innovation is a new or improved product or business process (or combination thereof) that differs significantly from the firm's previous products or business processes and that has been introduced on the market or brought into use by the firm. (OECD/Eurostat 2018: para. 3.9)

As with the previous editions of the Oslo Manual, for a product to be a product innovation, it must be 'introduced on the market' with the implication that the product is offered at economically significant prices (EC et al. 2009: para. 22.28). A process must be brought into use by the firm.

The definitions of innovation in the third and fourth editions of the Oslo Manual are similar (discussed in Chapter 6). This has the advantage that statistics gathered through surveys based on the Oslo Manual require little additional guidance of respondents. The example is the Community Innovation Survey (CIS) conducted by Eurostat every two years, the history of which, up to 2012, is reviewed by Arundel and Smith (2013). CIS questions are revised regularly, and modules are added to study 
topics of policy interest, while the definition remains essentially the same.

\subsubsection{Going beyond the Market}

The fourth edition of the Oslo Manual provides a general definition of innovation, applicable to all economic sectors, and the basic difference from previous definitions of business innovation is that the product innovation has to be 'made available to potential users', which is broader than 'introduced on the market'.

One of the ways of making a product available to potential users is to put it on the market at economically significant prices and that has been part of the definition of product innovation for decades and surveys have collected data that have populated indicators which are part of official statistics. However, there are other ways of making a product available to potential users, such as providing it at a price of zero or any other non-economically significant price. Products that are new or improved and differ significantly from the firm's previous products which are not introduced to the market but are made available to potential users at zero price do not appear in official statistics on product innovation. This is an issue, described briefly in Chapter 6, now that the digital economy is so prominent.

With the rise of the digital economy, 'potential users' are being offered, at zero price, new or improved products such as apps and updates to their apps, access to cloud storage or computing, software, hubs and social media. Other products, such as the Internet of Things, may be provided at economically significant prices. A characteristic of many of these products, in addition to those characteristics that make it an innovation, is that they come with a link between the producer and the user that allows the use of the product to be monitored and the information used for various purposes. While zero price products are increasingly shaping the way people think, work and interact with society, they can also be instruments of cybercrime.

There is at least as much justification for providing official statistics on zero price product innovations as for product innovation offered at economically significant prices. Statistics on both zero price and market price products should be available to policy developers and for monitoring and evaluation of existing policy interventions, leading to policy learning. There is an ongoing discussion of the products in the 
digital economy and their influence on the SNA (Diewert et al. 2018; Brynjolfsson et al. 2019).

\subsection{GENERAL GOVERNMENT SECTOR AND PUBLIC SECTOR}

General government consists of institutional units that, in addition to fulfilling their political responsibilities and their role of economic regulation, produce services (and possibly goods) for individual or collective consumption mainly on a non-market basis and redistribute income and wealth (EC et al. 2009: para. 2.17c).

The general government sector and the public sector are described in more detail in Chapter 22 of the 2008 SNA (EC et al. 2009: 435). The chapter starts with general government units which include some non-profit institutions (NPIs) and public enterprises not treated as corporations. The public sector includes general government and public corporations.

These are the institutional units which are the target for surveys of innovation in the general government sector and the public sector. Chapter 22 discusses how to identify the institutional units that belong in the general government and the public sector. Once the institutional units are identified a survey can follow, using the general definition of innovation to identify innovative units.

There is no manual on innovation in the general government sector or the public sector, although this has been discussed at the OECD over the years. The empirical work on public sector innovation is reviewed in Gault $(2012,2015,2016)$ and further discussed in the context of a general definition in Gault (2018a).

An early study of public sector innovation was the 2011 project for Measuring Public sector Innovation in the Nordic countries (MEPIN). The objective of the project was to develop a measurement framework for collecting internationally comparable data on innovation in the public sector in order to understand what public sector innovation is and how public sector organisations innovate. The measurement was expected to lead to indicators that could support the promotion of public sector innovation (Bloch and Bugge 2013). This is discussed in Gault (2015, 2018a).

To study public sector innovation, the OECD has created the Observatory of Public Sector Innovation (OPSI) which collects examples of innovation but does not propose a definition of public sector innovation. It does provide a platform to support a network of practitioners] and 
gathers information on case studies and work on public sector innovation. In addition, the EU has presented survey results and related information in the European Public Sector Innovation Scoreboard 2013 (EPSIS) (EC 2014).

Australia has been active in measuring public sector innovation and Arundel and Huber (2013: 146) have noted the absence of an agreed definition and used 'public sector innovation involves novelty and the intention of making something better, for instance through new or improved services or processes'. This definition of innovation raises questions about time scale and the meaning of 'better'. The authors have suggested that public sector managers think of innovation as improving the current state of the unit and they see 'innovation' as an ongoing process. This differs from the discussion of the definitions in Chapter 6 and raises a question about surveys, their development, cognitive testing and their use. Do you work with what the respondent thinks is the objective of the study or do you apply a standard definition, in this case of innovation, and then guide the respondent?

Ideally, an innovation survey should not use the word 'innovation'. Using the general definition, the first innovation question, as discussed, is about new or improved products or processes. The second, or it may be combined with the first, is about whether there is a significant difference from the unit's previous products or processes. The third question is about what was done with the product (made available to potential users?) or process (brought into use by the institutional unit?). Nowhere should the respondent be asked about 'innovation'. The survey instrument can be used as a means of teaching respondents about how to respond to the questions and once that is done, the statistician can infer the presence of innovation, as defined in the Oslo Manual, or not.

From the perspective of a manual for collecting and interpreting data from the public sector, Arundel et al. (2019: 789) have suggested that 'there is sufficient evidence, drawn from surveys of innovation in the public sector and cognitive testing interviews with public sector managers, to develop a framework for measuring public sector innovation'. This would bring together considerable experience from the MEPIN project and work in Australia (Arundel et al. 2015) to make a case that could be put to the OECD and the EU for the development of a manual. In the manual, the general definition of innovation could be applied to the public sector.

Manuals for statistical measurement of innovation, in different sectors, raise some questions. Since 1992, the OECD Working Party of National 
Experts on Science and Technology Indicators (NESTI) has been responsible for the guideline on the measurement of innovation in the business sector. From 1997, the relevant section of Eurostat became jointly responsible for the development and publication of the Oslo Manual. If there is to be a manual for the collection of information on innovation in the public sector, the household sector and the NPISH sector, there will have to be close cooperation with the relevant subject matter sections in the OECD and Eurostat. This is a potential challenge for the development of the subject of innovation measurement and related policy development.

\subsection{NON-PROFIT INSTITUTIONS SERVING HOUSEHOLDS}

NPISHs are legal entities that are principally engaged in the production of non-market services for households or the community at large and whose main resources are voluntary contributions (EC et al. 2009: para. 2.17e). NPISHs are not controlled by government.

Examples of NPISHs are professional or learned societies, political parties, trade unions, consumers' associations, churches or religious societies, and social, cultural, recreational or sports clubs (EC et al. 2009: para. 4.167). There is no manual for NPISH sector innovation, but the general definition of innovation can be applied.

\subsection{HOUSHOLD SECTOR}

Households are institutional units consisting of one individual or a group of individuals in a household. All physical persons in the economy must belong to one and only one household. The principal functions of households are to supply labour, to undertake final consumption and, as entrepreneurs, to produce market goods and non-financial (and possibly financial) services. The entrepreneurial activities of a household consist of unincorporated enterprises that remain within the household except under certain specific conditions (EC et al. 2009: para. 2.17d, para. 4.156). There is no manual for household sector innovation similar to the Oslo Manual for the business sector. As with other sectors without manuals on measuring innovation, the general definition can be applied.

Members of households may develop product or process innovations, but for them to be innovations they must be able to confirm that there is a new or improved product or process (or combination thereof) that 
differs significantly from the household's previous products or processes. They must then be able say that the product had been made available to potential users or that the process had been brought into use by the household's unincorporated enterprise.

The challenge in dealing with innovation in the household sector is classifying the household activity. If the activity is to run an unincorporated enterprise within a household, then it can be dealt with in the same way as the firms in the business sector; a product or process is identified satisfying the criteria of the general definition in the fourth edition of the Oslo Manual and the product has been made available to potential users or the process has been brought into use by the unincorporated enterprise. Larger unincorporated enterprises, such as law offices, can be treated as quasi-corporations in the business sector.

It is also possible for a household, including individuals in the household, to innovate by changing products acquired as consumers to enhance the benefit derived from the improved product. For there to be innovation, the product must be improved, and it must be made available to potential users. . The household could also create a product which was new if the product could not be found on the market. As with the improved product, it must be made available to potential users to be an innovation.

Work has been done on consumer innovation in households (von Hippel 1988, 2005, 2007, 2016, 2017; Harhoff and Lakhani 2016) where the focus has been on 'new or improved products' with less emphasis on the action of making them available to potential users. However, there is an active community engaged in this subject and it was during a study of user innovation for the government of Finland (de Jong et al. 2015) that the action making the product available to potential users was first discussed (Gault 2012). There were three means of making the product available to potential users: providing a prototype, or the knowledge needed to produce the prototype, to a firm that produced the product; starting a business to provide the product, or adding a new line of business to an existing business; or making the product available to potential users such as a peer group or a community of practice. The first two could be found in official innovation statistics, but not the third.

More needs to be done on household innovation which involves making the product available to peer groups or communities of practice. While there is a long history of studying household sector innovation (von Hippel 2017) the subject has yet to be brought into official statistics. 


\subsection{THE REST OF THE WORLD}

The sectors divide up the economic activity in the country, however, countries have borders and tangible and intangible things cross them in both directions. The Rest of the World (ROW) is discussed in Chapter 26 , 'The rest of the world accounts and links to the balance of payments' of the 2008 SNA. Where the ROW and the balance of payments statistics enter the innovation domain is in the linkages that connect institutional units in the country to those outside of the country. This is relevant to the study of global value chains and supply chains and their place in the study of innovation.

\subsection{CONCLUSION}

This chapter has introduced the SNA and the economic sectors of the SNA and it has explored the measurement of innovation, as defined in Chapter 6, in all economic sectors. This has raised questions about the absence of official statistics on innovation in all but the business sector and the impact on innovation statistics if innovation were measured everywhere. In the business sector, product innovations made available at zero price or, more generally, at non-economically significant prices, are not present in official statistics which is a significant gap in understanding innovation, especially in a digital economy.

The focus in this chapter has been on innovation in each economic sector. However, there are types of innovation that can happen in any economic sector and that is the subject of the next chapter.

\section{NOTES}

1. This may seem a more detailed discussion than is needed. However, there are researchers that dismiss innovation surveys as opinion surveys, not as statistical measurement of the activity of innovation. For the two components of the definition, the respondent will have an opinion about whether there is a new or improved product or process. The respondent should be able to distinguish whether the new or improved product or process differs significantly from previous products or processes, or not, and know whether the product has been made available to potential users or the process brought into use.

2 For readers not familiar with the SNA and GDP, consider Coyle (2016).

3. This is a decision needed to deal with an inconsistent use of households sector in the 2008 SNA. Households sector is used in Chapters 24 and 25 and 
household sector in most other chapters with some exceptions of which EC et al. (2009: para. 4.24) is one.

7. There was an attempt to capitalise R\&D in the SNA 1993 revision which failed. There were many considerations, one of which was that GDP would go up once R\&D was a capital expenditure and that would increase the cost of membership in some international organisations. Official statisticians noted that if R\&D were capitalised, it would be part of capital expenditure statistics which were an important part of the SNA. Innovation statistics are not part of the SNA.

5. Like innovation, cybercrime is everywhere. In the UK, it is taken very seriously. See https://www.nationalcrimeagency.gov.uk/what-we-do/crime -threats/cyber-crime (accessed 17 March 2020).

6. See http://nyskopunarvefur.is/files/filepicker/9/201102_mepin_report_web .pdf (accessed 17 March 2020).

7. See https://oecd-opsi.org/ (accessed 17 March 2020).

8. In addition to using the survey instrument as a means of guiding the respondent, it can also be used to teach the respondent about the subject being studied. See Gault (2013: 17).

9. 'Potential users' are just that, people or households that might benefit from using the product. 'Potential users' excludes people who are not likely to use the product. 